\title{
Accessibility of maternal health information and its influence on maternal health preferences in rural Tanzania: A case study of Chamwino District
}

Author:
Hilda A. Mwangakala 10
Affiliation:
'Department of Information
Systems and Technology,
Faculty of Informatics and
Virtual Education, The
University of Dodoma,
Dodoma, Tanzania
Corresponding author
Hilda Mwangakala,
ladyhmwa @gmail.com
Dates:
Received: 12 Nov. 2020
Accepted: 17 Aug. 2021
Published: 19 Oct. 2021
code with your
How to cite this article:
Mwangakala, H.A., 2021,
'Accessibility of maternal online.
health information and its
influence on maternal health
preferences in rural Tanzania:
A case study of Chamwino
District', South African
Journal of Information
Management 23(1), a1353.
https://doi.org/10.4102/
sajim.v23i1.1353
Copyright:
C 2021. The Authors.
Licensee: AOSIS. This work
is licensed under the
Creative Commons
Attribution License.

Background: The access to quality maternal health information amongst pregnant women plays an important role in determining woman's health behaviour during pregnancy. Yet, access to maternal health information remains a major challenge in Tanzanian rural communities especially for pregnant women leading to low utilisation of skilled maternal health services.

Objectives: The study aimed at examining the accessibility of maternal health information amongst pregnant women in rural Tanzania.

Methods: A qualitative phenomenological study involving 25 pregnant women, 5 skilled healthcare providers (SHPs) and 5 traditional birth attendants (TBAs) was carried out in Chamwino District, Dodoma Region, Tanzania for a period of 6 months. Data were analysed thematically using the six-stage guide to thematic data analysis with NVivo Software.

Results: The acute shortage of healthcare personnel and traditional beliefs influenced pregnant women's access to quality maternal health information. The majority of women used mothersin-law and TBAs as their primary source of maternal health information rather than skilled healthcare providers.

Conclusion: Despite the acute shortage, healthcare providers need to play a leading role in providing maternal health information amongst the rural populations. Furthermore, skilled health providers need to work in collaboration with the TBAs to increase access to maternal health information and build a well-informed healthy society.

Keywords: maternal health; skilled healthcare; health information; pregnant women; traditional birth attendant.

\section{Background}

Access to quality maternal health information amongst pregnant women plays an important role in determining a woman's health behaviour during pregnancy (Henwood et al. 2003; Sanders \& Crozier 2018; Say et al. 2014).

The research shows that knowledgeable people are more likely to take responsibility for their health (e.g. doing regular check-ups, compliance with treatment and vaccinations) and live healthier for longer than their uninformed counterparts (Clarke et al. 2016; Gray et al. 2005; Ransom et al. 2005; Wathen \& Harris 2007). People tend to seek health information because they believe that particular information will help them make informed health decisions and ultimately improve their health outcomes. However, access to health information is not uniform and varies between rural and urban dwellers (Chen et al. 2019).

Despite health information from healthcare professionals, studies show that generally, people tend to seek additional information from other sources such as relatives and friends for more detailed explanations on their health problems and are dependent on them for emotional support (Lin \& Chang 2018; Kreps 2005; Wathen \& Harris 2006). This highlights the existing gap between the offered health information and the actual needs of the community (Chang et al. 2004; Kreps 2005; Sokey \& Adisah-Atta 2017). The healthcare providers normally use the hospital visit encounters to offer required health information to patients including pregnant women. However, because of the limited time during encounters, generally, the information provided do not meet the information needs of the patients (Mwangakala 2016). People tend to need more information about their health problems rather than the short descriptions and instructions during hospital 
encounters (Chang et al. 2018; Sørensen et al. 2012; Tang et al. 1997; Weinstein \& Lopez 2014). Consequently, the failure of the healthcare provider to meet the patient's health information needs and expectations (Baker \& Pettigrew 1999; Clarke et al. 2016; Daltroy 1993; Francis, Korsch \& Morris 1969) aggravates the gap between the offered health information and the patient's actual information needs.

In most rural areas, well-equipped health facilities tend to be far away. The nearby health facilities are normally extremely understaffed with limited medical equipment and supplies. Furthermore, unlike in developed countries (Chen et al. 2018; Song et al. 2012), in most developing countries particularly in rural areas there is limited connectivity, therefore, TVs, radios and online health information are limited or inaccessible (Custodio, Gard \& Graham 2009; Sokey \& Adisah-Atta 2017; Van Zuuren \& Wolfs 1991). Thus, the only available credible source of maternal health information remains to be the healthcare professionals. However, as most medical facilities are understaffed, it is difficult for the few available health staff to meet the information needs of the patients and residents living in the area (Mwangakala 2016). This implies that access to health information from health professionals may not be an option either for the people or pregnant women living in rural areas (Doak et al. 1998; Nikiéma, Beninguisse \& Haggerty 2009; Sokey \& AdisahAtta 2017; Weinstein \& Lopez 2014). Hence, this study aimed at examining the accessibility of maternal health information and how pregnant women in the study population learn about maternal health.

Furthermore, given the latest statistics that show the maternal mortality rates of 556 deaths per 100000 live births in Tanzania (Alkema et al. 2016), the provision of adequate and relevant maternal health information is imperative (Mtega \& Benard 2013; Sokey, Adjei \& Ankrah 2018). Most studies show that the majority of maternal deaths are because of the non-utilisation of skilled health services, which is a result of a variety of factors ranging from cultural to socio-demographic factors to healthcare provider-related factors. Factors such as distance from health facilities, poverty, low-level of education and low status of women in society have become the most important limiting factors in many populations (Simkhada et al. 2008). Also, there are healthcare provider-related factors that significantly contribute to the failure of pregnant women to use skilled maternal services, for example, poor quality health services, costs associated with health services and poor treatment by healthcare workers in health facilities (Pokhrel \& Sauerborn 2004). However, the decision of pregnant women on whether or not to utilise skilled healthcare services does not depend entirely on sociodemographic factors but also on their knowledge of maternal health (Nikiéma et al. 2009), which depends on the access to maternal health information.

Previous studies have neglected to investigate the importance of maternal health information to pregnant women and how an individual's knowledge of maternal health impacts women's health behaviours. The accessibility of health information amongst pregnant women has been overlooked and under-researched (Nikiéma et al. 2009; Pokhrel \& Sauerborn 2004). Few studies in Africa (Nikiéma et al. 2009) have investigated the provision of health information to pregnant women during pregnancy. The research on rural women's access to maternal health information in Tanzania is still scarce. Therefore, the present study explored the adequacy of maternal health information amongst pregnant women in rural Tanzania and the actual health information needs.

\section{Research methods and design Study design}

The study used a qualitative phenomenological research design because the goal was gaining understanding from the perspectives of the people living the experience on beliefs, perceptions, interpretations about the accessibility of maternal health information. The researcher examined individual women's experiences on accessing maternal health information, the pregnant women were asked to describe their experiences as they perceive them. The phenomenology design helped the researcher to affirm the legitimacy of the knowledge and perceived truth about women's access to maternal health information as the participants are perceived to be experts about the investigated phenomenon (Mwangakala 2016).

Focus groups and semi-structured interviews were used to explore the accessibility of maternal health information and how pregnant women learnt about maternal health. Although the interviewer had established a precise set of topics to be covered, the method allowed for exploration of the themes and ideas that arise during the process rather than relying on the predefined fixed concepts and questions. Focus groups provided a supportive environment in which pregnant women were able to freely discuss matters concerning maternal health in their community (Mwangakala 2016).

\section{Study setting}

This study focused on understanding the accessibility of maternal health information amongst pregnant women in rural areas. Therefore, the most suitable study site was a population in a rural area with access to health facilities providing maternal services but where the low usage of skilled healthcare services is most evident.

The study was carried out in Chamwino District, one of the seven administrative districts of Dodoma Region in Tanzania for a period of six months. The researcher selected two wards from the administrative divisions where the problem of low utilisation of skilled maternal healthcare was most prominent. These two selected wards were Msanga and Buigiri, each consisting of at least 10 villages with 4 to 6 sub-villages each. A typical village generally has an average population size of 1000 people. Therefore, research participants were selected from five sub-villages of the two wards: Chang'ombe, Kibiriti, Kolongo, Makulu B, Kihamba and sub-villages. 


\section{Study population and sampling strategy}

The study used purposive sampling to select study participants where the participants were carefully selected to get community members who are information-rich and homogeneous to facilitate the reaching of the saturation point. Taking this into consideration, the study participants consisted of 35 participants with 25 pregnant women, 5 traditional birth attendants (TBAs) and 5 healthcare staff in the selected communities.

To identify the available pregnant women in the population, the researcher visited the two health facilities in the two chosen wards and requested for the maternity register, which also provided access to the names and locations of the identified pregnant women (Mwangakala 2016). Furthermore, to reach other pregnant women who had not yet started visiting health facilities for antenatal (ANC) clinic, the researcher enlisted the help of community health workers and community leaders to identify available pregnant women in their communities to ensure that the study involves as many pregnant women as possible. During participants' selection, a total of 29 pregnant women were requested to participate in the study. However, only 25 women consented to take part in the study whilst the other 4 were not ready to participate.

On the other hand, the selection of skilled healthcare providers (SHPs) was dependent on the number of health staff available in a particular health facility. The participants' selection criteria were that the particular health staff deals with pregnant women's health. In the first dispensary in Buigiri ward: one clinical officer (CO), one nurse and one reproductive and child health aider (RCHA) were selected and interviewed. Whereas in the second dispensary in Msanga ward: two nurses were interviewed, as both nurses were responsible for providing maternal care services to pregnant women in the area. The TBAs' selection was random and it was also subject to their availability and preparedness to participate in the study. Five TBAs were selected from the two wards: Three from Buigiri ward and the other two from Msanga ward.

\section{Data collection}

The semi-structured interviews were used to explore rural pregnant women's opinions and experiences regarding accessibility of maternal health information. The tool allowed the interviewer to facilitate the respondents to express their views and experiences on the social phenomenon by probing without imposing opinions and experiences on the respondents (Mwangakala 2016). It was also very useful in gathering information from rural populations whose voices are rarely heard. They normally have experiences and knowledge that are excluded from the general understanding of social reality (Hesse-Biber \& Leavy 2010), hence the use of semi-structured interviews allowed pregnant women and healthcare providers living in rural areas to express issues that were based on personal experiences and specific to their population.
The interviews were conducted at pregnant women's homes, and each interview lasted between $45 \mathrm{~min}$ and $1 \mathrm{~h}$. Semistructured interviews were also used to gather information from TBAs and SHPs who attend pregnant women during their visits to the health facilities. The interview guides for TBAs and SHPs contained similar categories to allow comparison on the types of health information that was provided to pregnant women.

As there was a severe shortage of health staff in the respective health facilities, the interviews with SHPs had to take into account their time limitations and location of the interview. Therefore, to reduce inconvenience and service interruptions for patients, the interviews were conducted in the afternoons at the respective dispensary when all the patients had already left the facility. The interviews were carried out in Swahili and lasted between $1 \mathrm{~h}$ and $1.5 \mathrm{~h}$.

Moreover, TBAs represented local/traditional maternal care providers. The interviews with TBAs were conducted at their homes and lasted for at least $1 \mathrm{~h}$. The interview with SHP and TBAs focused on the content and frequency of maternal health information they offered to pregnant women. All sessions were recorded using a digital voice recorder.

Furthermore, the researcher conducted four focus groups with pregnant women to supplement data collected through semi-structured interviews. Focus groups were used because it was assumed that the respondents might withhold some information during individual interviews because of fear or sensitivity of the information. However, when other group members discussed similar information, women opened up and spoke up because they felt less pressured and could not be easily identified. The interactions and inquiries on each other's comments about their perceptions on maternal health information accessibility resulted in revealing the hidden opinions and concerns that were not revealed during interviews (Mwangakala 2016).

\section{Data analysis}

The collected data were transcribed in Swahili and later translated into English. The data were thematically analysed using the six-stage guide to thematic data analysis with the help of Nvivo 10.0, a software for qualitative data analysis as follows:

\section{Becoming familiar with the data}

The majority of pregnant women had negative feelings about the maternal health information provided when visiting the health facilities. Most women felt ignored, the healthcare providers were not giving them the support they needed and were not concerned that they knew very little about pregnancy health. As a result, they sought maternal health information and learnt about maternal health from other sources such as their mothers-in-law, TBAs and fellow older women in the community. 


\section{Generating initial codes}

The researcher coded each segment of data that was relevant to or captured something interesting about how pregnant women accessed and learnt about maternal health. As the researcher used open coding, hence the codes were developed and modified while working through the coding process. The transcripts were separately analysed to obtain the patterns and concepts that emerged during each interview. For instance, non-provision of any health information by healthcare providers and mistreatment came up in almost all interviews and group discussions. Hence, the researcher read through all the transcripts and generated initial codes with the help of Nvivo 10.0. The initial coding resulted in 208 codes, which were categorised and reduced to 90 codes as shown in Table 1.

\section{Searching for themes}

Similar patterns and concepts were stored in nodes. The nodes were categorised and re-categorised to generate the potential themes and sub-themes emerging within and across the gathered data. For example, we had several codes that related how pregnant women perceived the maternal healthcare services and health information provided and what women wished to learn about maternal health. The researcher collated these into an initial theme called maternal health information provision and attitudes towards healthcare services. Table 2 shows all the preliminary themes that were identified along with the codes that are associated with them. Most codes were associated with one theme although some were found to be associated with more than one theme (these are highlighted in Table 2).

\section{Reviewing themes}

The researcher reviewed, modified and developed the preliminary themes that were identified in Step 3. All the data that were relevant to each theme were gathered and considered irrelevant of whether the data really did support it. The researcher then assessed whether the themes work in the context of the entire data set and the research question. The themes that did not have enough supporting data were eliminated and new themes were developed that better captured what participants were saying about accessibility of maternal health. The final themes are shown in Table 3.

\section{Defining themes}

During this stage, the researcher ascertained what each theme is about and how does it relate and interact with sub-themes. Results sections illustrate what each theme is about the relationship between themes. And the sixth stage was a write-up.

\section{Ethical considerations}

The research study involved pregnant women who are in the category of a vulnerable group, therefore, the ethical questions of the human participants were taken seriously. Prior to the start of the study, ethical approval was obtained from the Ethical Advisory Sub-committee of Loughborough University, United Kingdom. Furthermore, at the study site, the study permit was issued by the office of the District Medical Officer (DMO). The permit allowed the researcher to interview pregnant women and nurses and to access the maternity registers available at the health facilities.

Prior to the interview, each participant was informed about the study objectives. Participants also received or were read

TABLE 1: List of final codes.

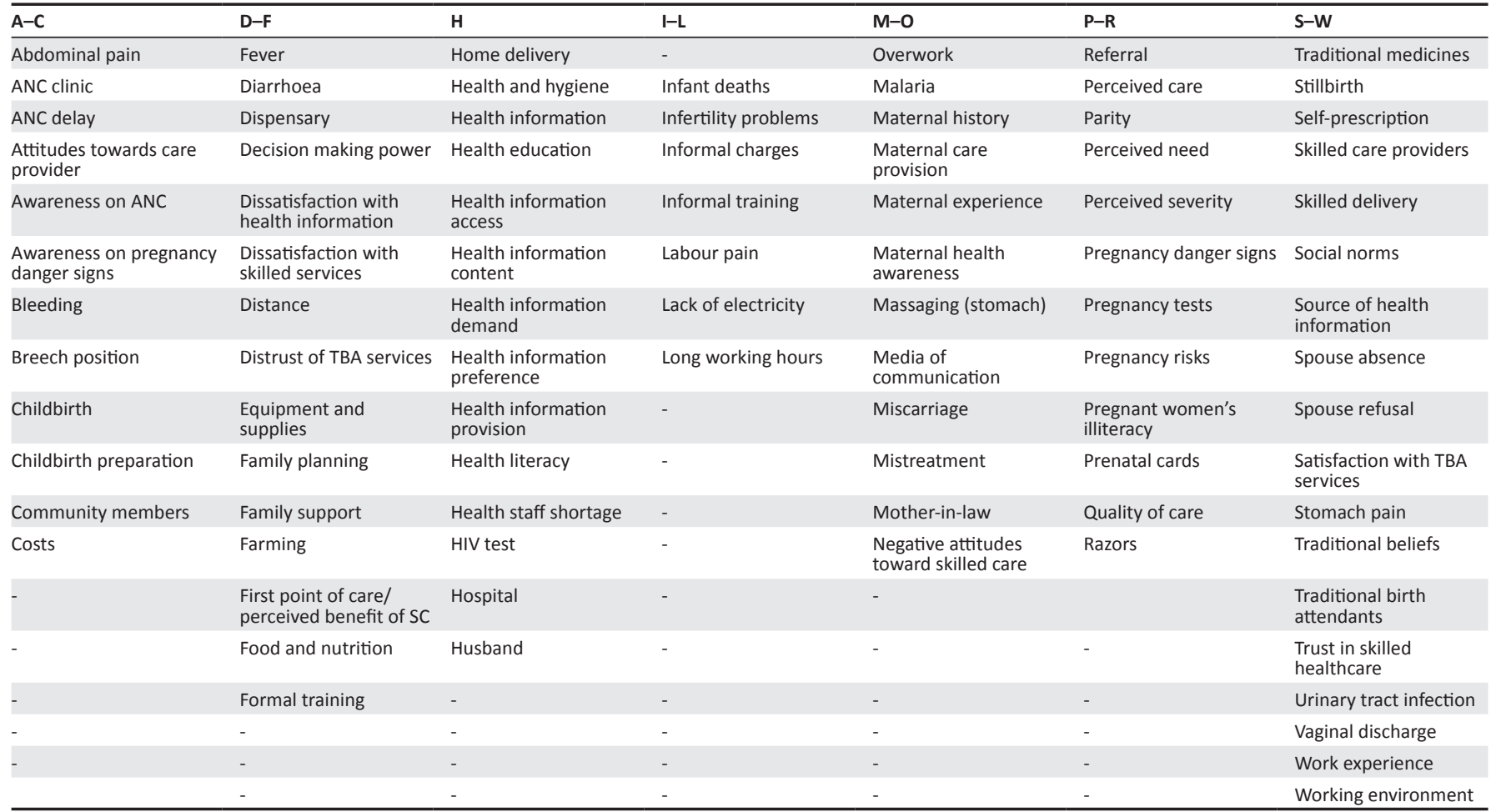

TBA, traditional birth attendant. ANC, antenatal care. 
TABLE 2: Preliminary themes.

\begin{tabular}{|c|c|}
\hline Theme & Codes \\
\hline \multirow[t]{13}{*}{ Attitude towards healthcare services } & Attitudes towards care provider \\
\hline & Dissatisfaction with skilled services \\
\hline & $\begin{array}{l}\text { Dissatisfaction with health } \\
\text { information }\end{array}$ \\
\hline & $\begin{array}{l}\text { First point of care/perceived } \\
\text { benefit of SC }\end{array}$ \\
\hline & Informal charges \\
\hline & Informal training \\
\hline & Lack of electricity \\
\hline & Long working hours \\
\hline & Self-prescription \\
\hline & Mistreatment \\
\hline & Negative attitudes toward skilled care \\
\hline & Pregnancy tests \\
\hline & Trust in skilled healthcare \\
\hline \multirow[t]{9}{*}{ Health information preferences } & Childbirth preparation \\
\hline & Family planning \\
\hline & Food and nutrition \\
\hline & Health information preference \\
\hline & Health information demand \\
\hline & Media of communication \\
\hline & Perceived need \\
\hline & Pregnancy danger signs \\
\hline & Pregnancy risks childbirth \\
\hline \multirow[t]{18}{*}{ Maternal health services } & ANC clinic \\
\hline & ANC delay \\
\hline & Costs \\
\hline & Distrust of TBA services \\
\hline & Equipment and supplies \\
\hline & Distance \\
\hline & Formal training \\
\hline & Health information access \\
\hline & Health information content \\
\hline & Health staff shortage \\
\hline & HIV test \\
\hline & Home delivery \\
\hline & Maternal care provision \\
\hline & Overwork \\
\hline & Prenatal cards \\
\hline & Quality of care \\
\hline & Referral process \\
\hline & Skilled delivery \\
\hline \multirow{16}{*}{$\begin{array}{l}\text { Maternal health Information } \\
\text { provision }\end{array}$} & Awareness on ANC \\
\hline & $\begin{array}{l}\text { Awareness on pregnancy danger } \\
\text { signs }\end{array}$ \\
\hline & Childbirth \\
\hline & Childbirth preparation \\
\hline & Family planning \\
\hline & $\begin{array}{l}\text { Dissatisfaction with health } \\
\text { information }\end{array}$ \\
\hline & Health and hygiene \\
\hline & Health information \\
\hline & Health education \\
\hline & Health information access \\
\hline & Health information content \\
\hline & Health information provision \\
\hline & Health literacy \\
\hline & Maternal health awareness \\
\hline & Pregnant women's illiteracy \\
\hline & Source of health information \\
\hline
\end{tabular}

Table 2 continues on the next column $\rightarrow$
TABLE 2 (Continues...): Preliminary themes.

\begin{tabular}{ll}
\hline Theme & Codes \\
\hline Pregnancy health & Abdominal pain \\
& Bleeding \\
& Breech position \\
& Fever \\
& Infant deaths \\
& Infertility problems \\
& Miscarriage \\
& Pregnancy danger signs \\
& Stillbirth/cues to action \\
& Urinary tract infection \\
& Vaginal discharge \\
Community members' support \\
Decision making power \\
Distrust of TBA services \\
Family support \\
Home delivery \\
Massaging (stomach) \\
Mother-in-law roles \\
Spouse refusal \\
Satisfaction with TBA services \\
Traditional birth attendants \\
Traditional beliefs \\
Traditional medicines \\
\hline
\end{tabular}

TBA, traditional birth attendant. ANC, antenatal care.

\begin{tabular}{|c|c|}
\hline Theme & Sub-theme \\
\hline $\begin{array}{l}\text { Health information } \\
\text { preferences }\end{array}$ & $\begin{array}{l}\text { Pregnant women health information needs } \\
\text { Childbirth preparation } \\
\text { Food and nutrition } \\
\text { Family planning } \\
\text { Health information demand } \\
\text { Health information preference } \\
\text { Media of communication } \\
\text { Pregnancy danger signs } \\
\text { Pregnancy risks } \\
\text { Perceived need } \\
\text { When to start ANC clinic }\end{array}$ \\
\hline $\begin{array}{l}\text { Sources of maternal } \\
\text { health information }\end{array}$ & $\begin{array}{l}\text { Provision of maternal health at health facilities } \\
\text { Awareness on pregnancy danger signs } \\
\text { ANC delay because of low awareness and poor services } \\
\text { Abdominal pain } \\
\text { Dissatisfaction with health information } \\
\text { First point of care/Perceived benefit of SC } \\
\text { Low awareness on ANC } \\
\text { Pregnancy danger signs } \\
\text { Role of mothers-in-law in decision making } \\
\text { Traditional birth attendants } \\
\text { When to start ANC clinic }\end{array}$ \\
\hline $\begin{array}{l}\text { Quality of Maternal } \\
\text { health information }\end{array}$ & $\begin{array}{l}\text { Attitude towards healthcare services } \\
\text { Attitudes towards care provider } \\
\text { Dissatisfaction with health information provided } \\
\text { Dissatisfaction with skilled services } \\
\text { Dissatisfaction with health information } \\
\text { First point of care/perceived benefit of SC } \\
\text { Informal healthcare charges } \\
\text { Lack of electricity and use of lamps such as TBAs } \\
\text { Lack of concern by healthcare providers } \\
\text { Self-prescription because of lack of medicines at the } \\
\text { health facilities } \\
\text { Trust in skilled healthcare }\end{array}$ \\
\hline
\end{tabular}

TBA, traditional birth attendant. ANC, antenatal care. 
the 'Participant's Information Sheet' and the 'Informed Consent Form'. The researcher explained to the participants the research modalities: study aim and objectives, the scope of their participation, the number of times they will meet with the researcher, the nature of the meetings and the type of questions that are asked. The researcher also explained to the participants that their participation in the study was completely voluntary and that they could opt out at any time without having to explain why they have chosen to opt-out. Participants were also reassured that their participation was confidential and that all conversations during interviews would be anonymous. The Participants' Information Sheet containing all the information about their participation, confidentiality and privacy was made available to all participants and for those who could not read the researcher read the information sheet to them.

To ensure confidentiality and anonymity, each interview transcript was given a unique reference number, the reference number indicated the source (I for interview and FG for focus group), the first two letters of participant's name and lastly the village name, for example, 'IStKibiriti' mean the interview response from the participant with first two letters ' $\mathrm{St}$ ' from Kibiriti village. Whereas for the health staff they were assigned numbers, for example, Nurse 1 . As described in the information sheet, not one participant's name was used anywhere in the documentation.

\section{Results}

\section{Population demographics characteristics}

The pregnant women in the study were aged between 18 and 41 years, the majority of women were between the age of 25 and 35 years $(52 \%)$ with a mean age of 28.04 (see Table 4 ). As, they start childbearing at a young age, on an average the woman in the study population would have between five and seven children by the end of her reproductive period. The mean number of births to women participants of age 35-41 years was 6.6 children.

The literacy level amongst pregnant women in the study population was very low. About half $(n=13)$ of the participants did not complete primary school education and $40 \%(n=11)$ amongst them could not read or write. The remaining $48 \%$ $(n=12)$ women completed their primary education but had not continued to attain further education (Table 5).

The study also assessed the access of pregnant women to various media to obtain information on maternal health. Women were asked if they had access to any of the following media: mobile phones, radio, television or newspaper at least once a week. A total of $64 \%(n=16)$ of pregnant women did not have access to any type of media for health information. Only 6 (24\%) participants had access to mobile phones and the other 3 $(12 \%)$ could access the radio at least once a week (Table 6).

\section{Sources of maternal health information}

The community in the study population was a very traditional society, men and women had distinct roles and responsibilities.
TABLE 4: Pregnant women's education and parity.

\begin{tabular}{lcc}
\hline Background characteristics & Number of participants & Percentage \\
\hline Age (years) & 3 & \\
$15-19$ & 5 & 12 \\
$20-24$ & 11 & 20 \\
$25-34$ & 6 & 44 \\
$35-44$ & & 24 \\
Parity & 3 & \\
Null parous & 13 & 12 \\
Uniparous & 9 & 52 \\
Multiparous & & 36 \\
\hline
\end{tabular}

TABLE 5: Pregnant women's education level.

\begin{tabular}{lcc}
\hline Background characteristics & Number of participants & Percentage \\
\hline Education level & 10 & 40 \\
No education & 3 & 12 \\
Some primary school & 12 & 48 \\
Completed primary school & 0 & 0 \\
Secondary school education & &
\end{tabular}

TABLE 6: Pregnant women's access to information media.

\begin{tabular}{lcc}
\hline Background characteristics & Number of participants & Percentage \\
\hline Media access (< Once a week) & 3 & 12 \\
Radio & 0 & 0 \\
Newspaper & 6 & 24 \\
Mobile phones & 0 & 0 \\
Television & 16 & 64 \\
No Media &
\end{tabular}

For instance, household chores, child care and pregnancy health was solely a woman's responsibility (Mwangakala 2016). It was found that most pregnant women used TBAs, mothers-in-law and older women as their primary source of health information rather than healthcare providers. Thus, when a pregnant woman had any issue about pregnancy she would usually go to the mother-in-law for advice. In young families, the mothers-in-law played a major role in maternal health, they were responsible for all decisions pertaining to women's health. They decided when a pregnant woman should start attending ANC clinic, where to go if any problem arises during pregnancy or where to go for childbirth services. As the key decision-maker, most pregnant women normally sought maternal health advice and health information from them:

'It is my first pregnancy so I asked my mother-in-law when I should start ANC and she told me I should wait until the pregnancy is at least six months, so I'm waiting.' (IMaKibiriti)

'Last month I had severe cramps the whole night when I told my husband and mother-in-law, my mother-in-law said stomach pains are normal for pregnant women so I should just lie down and the pain will stop itself. I didn't go to the hospital.' (IPaKihamba)

'I didn't start attending ANC clinic earlier because my motherin-law said I should wait until the pregnancy is at least six months old. It is my first pregnancy I didn't know when to start so I asked her.' (IEs Kihamba)

The TBAs as care providers were also used as a primary source of maternal health information. They are highly respected and trusted members of the society and their 
services were widely used by pregnant women in the study population. The pregnant women regarded them as experienced and knowledgeable about maternal health issues, hence, whenever they wanted to learn anything or have any difficulty in pregnancy, they sought the help and advice of the TBA in the area:

'My mother-in-law is a TBA she told me about some of the danger signs. She said if I start bleeding or have severe cramps that means something is wrong with the pregnancy, I should tell her immediately.' (IPenKolongo)

'The TBA does not live far from here so if I have any problem or I want to know anything about pregnancy I just go to ask her and she takes care of it. Last month I had some severe cramps and I told her, she messaged me and gave me some traditional medicine, it stopped after a few days.' (IStKihamba)

'I once had cramps and went to the TBA, she said it is not something to worry about she massaged my stomach and the pain stopped. But she told me that if I bleed that is a problem I should go to the dispensary.' (Ian Makulu)

Unlike in other rural populations (Clarke et al. 2016; Kwesigabo et al. 2012; Tsehay 2014) where pregnant women seek the maternal health information from health extension workers, in this study very few women reported using SHPs as their primary source of health information.

The lack of maternal health information from SHPs could also partly explain why most rural pregnant women still preferred TBAs and mother-in-law as their primary source of maternal health information.

\section{Quality of maternal health information}

The study revealed that very few pregnant women had access to maternal health information from SHPs. Hence, the researcher enquired the healthcare providers on the quality of the maternal health information offered to pregnant women during ANC visits. The healthcare providers reported that because of the acute shortage of health staff and a large number of patients, they sometimes lack time to talk to pregnant women about maternal health:

'We try our best to provide health information every time they come for ANC clinic. However, there are days when I'm alone and there are too many patients, I find it hard to get time to talk to women about pregnancy health. But when they come in the next visits, we try to teach them.' (NurseM2)

'In days where we have several clinics, for example, children clinic, maternal clinic, and other patients, it is impossible to offer any health education to pregnant women. Sometimes I even forget to conduct basic health checks such as blood pressure, but we try our best.' (NurseB1)

'We try our best to offer maternal health information to pregnant women every time they come for ANC visit, but sometimes we have too many patients at the dispensary and we don't get time to talk to pregnant women.' (NurseB2)

Moreover, the healthcare providers also reported that the majority of women in the population had low literacy thus needed close attention when discussing maternal health.
However, because of the acute shortage of health staff, it was impossible to meet the individual needs of these women.

Generally, pregnant women did not have access to skilled maternal health information during ANC visits and even those who were given health information did not receive an adequate amount of maternal health information to influence their health behaviours. The majority of pregnant women were not aware of the recommended time in pregnancy to start to attend ANC clinics. Early ANC attendance was not emphasised by the skilled care providers because many pregnant women reported not to be given that information at the clinic even in previous pregnancies:

'No, I don't know the nurse didn't tell me when I went to the ANC clinic. But I plan to start attending ANC next month my pregnancy will be five months old ....' (ISpKolongo)

'I'm not sure when exactly we are supposed to start ANC because I was never told before. But I had a complication about two months ago and I went to the dispensary for a check-up, the nurse registered me for ANC too.' (IPaKihamba)

'No, I don't know, the nurses do not tell us about those things when we go for antenatal care services, each woman decides on herself when to start ANC clinic.' (FG3 Roz)

'No, I don't know and I have not yet started the antenatal clinic in this pregnancy. But even in my previous pregnancy, I don't remember being told about it.' (ITaKolongo)

The first-time mothers used their mothers or mothers-inlaw to confirm their pregnancies. Therefore, most of the first-time mothers became aware of the ANC clinic through mothers, mothers-in-law and TBAs. The major setback of these sources of health information is that it was dependent on the individual's perceptions and attitude towards ANC.

The lack of awareness on the recommended antenatal care attendance led to the majority of the women to delay ANC than recommended. Most women started ANC clinic when the pregnancy was 5 months or older causing the majority of pregnant women not to meet the minimum required number of four ANC visits during pregnancy.

Furthermore, most pregnant women were not aware of the pregnancy danger signs and had very little knowledge of how to manage the danger signs or complications when they arise. The majority of women in this group were first-time mothers and although some had already attended the ANC clinic more than once, they were still unaware of any pregnancy danger signs. The lack of reliable maternal health information on pregnancy danger signs affected the way pregnant women in the study population perceived the severity of danger signs (Mwangakala 2016). This caused most pregnant women to assume that the pregnancy danger signs are harmless revealing the existing low maternal health literacy.

Nevertheless, the maternal health information needs amongst pregnant women vary considerably. The results show that 
TABLE 7: Pregnant women information needs.

\begin{tabular}{lll}
\hline Preference & $\begin{array}{l}\text { Older pregnant women } \\
(>25 \text { years })\end{array}$ & $\begin{array}{l}\text { Younger pregnant women } \\
(\mathbf{1 8 - 2 5} \text { years) }\end{array}$ \\
\hline 1 & Family planning & Pregnancy danger signs \\
2 & Childcare & Labour and childbirth \\
3 & Miscarriage prevention & Pregnancy care \\
4 & Danger signs & Family planning \\
5 & Nutrition and diet & Childbirth preparation \\
6 & Labour and childbirth & Nutrition and diet \\
7 & Childbirth preparation & Antenatal care \\
\hline
\end{tabular}

there is a difference in preference for maternal health information between younger women and older ones (Table 7). For example, younger women preferred health information about pregnancy, danger signs and labour and childbirth, whilst older women preferred information on family planning and child care.

\section{Discussion}

The study examined the accessibility of maternal health information amongst pregnant women in rural areas and how they learnt about maternal health. Similar to the findings in other studies (Naanyu et al. 2013; Sokey \& Adisah-Atta 2017), most pregnant women could not access maternal health information from SHPs. As the findings show that distance was not a significant factor as some pregnant women were living near the health facility and yet did not prefer health facilities as their first point of care. The limited access to maternal health information could be because of an acute shortage of healthcare staff making it impossible to meet the health information needs of these women. Corresponding to previous studies (Clarke et al. 2016; Doak et al. 1998; Tsehay 2014; Van Zuuren 1991), the limited health facilities and poor working conditions affected the provision of adequate and quality health information to rural dwellers leading to poor utilisation of skilled health services.

Moreover, the majority of women reported not to seek skilled healthcare when experienced a health problem, some reported to go to the TBAs and very few reported to go to the hospital immediately when feeling unwell. It was apparent that the pregnant women's low utilisation of skilled health services was the result of the health information they received from their mothers-in-law and some by the TBAs. Nonetheless, despite the shortcomings of the information inaccuracy, usage of TBA services is inevitable and they still play a major role in rural pregnant women's health. The SHPs also acknowledged the existence and effect of other sources of maternal health information in pregnant women's healthcare-seeking behaviour. Hence, there is a need for the government to effectively engage the TBAs and use the traditional media in health information dissemination and promotion of health programmes. The health information messages could be communicated through songs, drama, town criers and women leaders, role play and stories during the antenatal clinic visits (Lambert \& Loiselle 2007; Sokey \& Adisah-Atta 2017; Sokey et al. 2018). The researcher argues that, unless the pregnant women in rural areas understand the real danger of pregnancy-related danger signs, they are less likely to timely seek and utilise the required skilled maternal care (Naanyu et al. 2013; Sokey et al. 2018).

\section{Conclusion}

Access to proper maternal health information influenced how pregnant women react towards ill health and in monitoring their health during pregnancy. Therefore, despite the shortage, the healthcare providers need to play a leading role in meeting the health information needs of the rural populations to build a well-informed society that is responsible for their own health and takes better health decisions. The provision of relevant health education and information about maternal health to TBAs and mothers-inlaw will positively influence pregnant women's healthcare utilisation behaviour especially young mothers as they are likely to access and act on the information passed on by TBAs and their mothers-in-law.

Furthermore, as other means of health information access, such as TV or internet are not an option for the majority of rural women and that a small number of women has access to radio, other media channels for health information need to be developed to improve women's access to maternal information. Visual aids such as posters, picture magazines, leaflets, drama, songs and plays could be used to facilitate access to maternal health information amongst rural populations. The use of popular, interesting and understandable information materials for women and the community at large will not only increase women's access to maternal health information but also facilitate health information-seeking behaviour.

The study focused on the existing sources of maternal health information, thus future studies may explore the role of technology such as basic mobile phones and social media in increasing rural women's access to maternal health information.

\section{Acknowledgements}

The author would like to thank her colleagues at the University of Dodoma for their invaluable comments and feedback. The author is also thankful to all the respondents who participated in this study.

\section{Competing interests}

The author declares that she has no competing interest in relation to the publication of this article.

\section{Author's contributions}

The author was responsible for the primary research and write-up of the article.

\section{Funding information}

This study was primarily funded by Commonwealth Scholarship Commission (grant number TZCS-2012-533). Additional support was provided by Loughborough University. 


\section{Data availability}

Any data that support the findings of this study are included within the article.

The author declares that the article is based on her PhD thesis that has already been published in Loughborough University's repository but this article has not been published elsewhere and that it has not been submitted simultaneously for publication somewhere else.

\section{Disclaimer}

The views and opinions expressed in this article are those of the author and do not necessarily reflect the official policy or position of any affiliated agency of the author, and the Publisher/s.

\section{References}

Alkema, L., Chou, D., Hogan, D., Zhang, S., Moller, A.B., Gemmill, A. et al., 2016 'Global, regional, and national levels and trends in maternal mortality between 1990 and 2015, with scenario-based projections to 2030: A systematic analysis by the UN Maternal Mortality Estimation Inter-Agency Group', The Lancet 387(10017), 462-474. https://doi.org/10.1016/S0140-6736(15)00838-7

Baker, L.M. \& Pettigrew, K.E., 1999, 'Theories for practitioners: Two frameworks for studying consumer health information-seeking behavior', Bulletin of the Medical Library Association 87(4), 444-450.

Chang, B.L., Bakken, S., Brown, S.S., Houston, T.K., Kreps, G.L., Kukafka, R. et al., 2004, 'Bridging the digital divide: Reaching vulnerable populations', Journal of the American Medical Informatics Association 11(6), 448-457. https://doi.org/10.1197/jamia.M1535

Chen, X., Hay, J.L., Waters, E.A., Kiviniemi, M.T., Biddle, C., Schofield, E. et al., 2018 'Health literacy and use and trust in health information', Journal of Health Communication 23(8), 724-734. https://doi.org/10.1080/10810730.2018.1511658

Chen, X., Orom, H., Hay, J.L., Waters, E.A., Schofield, E., Li, Y. et al., 2019, 'Differences in rural and urban health information access and use', The Journal of Rural Health 35(3), 405-417. https://doi.org/10.1111/jrh.12335

Clarke, M.A., Moore, J.L., Steege, L.M., Koopman, R.J., Belden, J.L., Canfield, S.M. et al., 2016, 'Health information needs, sources, and barriers of primary care patients to achieve patient-centered care: A literature review', Health Informatic Journal 22(4), 992-1016. https://doi.org/10.1177/1460458215602939

Custodio, R., Gard, A.M. \& Graham, G., 2009, 'Health information technology: Addressing health disparity by improving quality, increasing access, and developing workforce', Journal of Health Care for the Poor and Underserved 20(2) 301-307. https://doi.org/10.1353/hpu.0.0142

Daltroy, L.H., 1993, 'Doctor-patient communication in rheumatological disorders', Baillière's Clinical Rheumatology 7(2), 221-239. https://doi.org/10.1016/S0950Baillière's Clinical
3579(05)80087-1

Doak, C.C., Doak, L.G., Friedell, G.H. \& Meade, C.D., 1998, 'Improving comprehension for cancer patients with low literacy skills: Strategies for clinicians', CA: A Cancer Journal for Clinicians 48(3), 151-162. https://doi.org/10.3322/canjclin.48.3.151

Eschenfelder, K.R., 2004, 'Behind the Web site: An inside look at the production of Web-based textual government information', Government Information Quarterly 21(3), 337-358.

Francis, V., Korsch, B.M. \& Morris, M.J., 1969, 'Gaps in doctor-patient communication Patients' response to medical advice', New England Journal of Medicine 280(10), 535-540. https://doi.org/10.1056/NEJM196903062801004

Gray, N.J., Klein, J.D., Noyce, P.R., Sesselberg, T.S. \& Cantrill, J.A., 2005, 'Health informationseeking behaviour in adolescence: The place of the internet', Social Science \& Medicine 60(7), 1467-1478. https://doi.org/10.1016/j.socscimed.2004.08.010

Henwood, F., Wyatt, S., Hart, A. \& Smith, J., 2003, "Ignorance is bliss sometimes": Constraints on the emergence of the "informed patient" in the changing landscapes of health information', Sociology of health \& IIIness 25(6), 589-607. landscapes of health information', Sociology
https://doi.org/10.1111/1467-9566.00360

Hesse-Biber, S.N. \& Leavy, P., 2010, 'The practice of qualitative research', Sage, Thousand Oaks, CA.
Kwesigabo, G., Mwangu, M.A., Kakoko, D.C., Warriner, I., Mkony, C.A., Killewo, J. et al., 2012, 'Tanzania's health system and workforce crisis', Journal of Public Health Policy 33(1), S35-S44. https://doi.org/10.1057/jphp.2012.55

Kreps, G.L., 2005, 'Disseminating relevant health information to underserved audiences: Implications of the Digital Divide Pilot Projects', Journal of the Medical Library Association 93(4 Suppl), S68-S73.

Lambert, S.D. \& Loiselle, C.G., 2007, 'Health information - Seeking behavior', Qualitative Health Research 17(8), 1006-1019. https://doi.org/10.1177/1049732307305199

Lin, H.C. \& Chang, C.M., 2018, 'What motivates health information exchange in social media? The roles of the social cognitive theory and perceived interactivity', Information \& Management 55(6), 771-780.

Mtega, W.P. \& Ronald, B., 2013, 'The State of Rural Information and Communication Services in Tanzania: A Meta-Analysis', International Journal of Information and Communication Technology 3(2), 64-73.

Mwangakala, H.A., 2016, 'Pregnant women's access to maternal health information and its impact on healthcare utilization behaviour in rural Tanzania', Doctoral dissertation, Loughborough University.

Naanyu, V., Baliddawa, J., Peca, E., Karfakis, J., Nyagoha, N. \& Koech, B., 2013, 'An examination of postpartum family planning in western Kenya: "I want to use contraception but I have not been told how to do so"', African Journal of Reproductive Health 17(3), 44-53.

Nikiéma, B., Beninguisse, G. \& Haggerty, J.L., 2009, 'Providing information on pregnancy complications during antenatal visits: Unmet educational needs in subSaharan Africa', Health Policy and Planning 24(5), 367-376. https://doi. org/10.1093/heapol/czp017

Pokhrel, S. \& Sauerborn, R., 2004, 'Household decision-making on child health care in developing countries: the case of Nepal', Health Policy and Planning 19(4), 218-233.

Ransom, S., Jacobsen, P.B., Schmidt, J.E. \& Andrykowski, M.A., 2005, 'Relationship of problem-focused coping strategies to changes in quality of life following treatment for early stage breast cancer', Journal of Pain and Symptom Management 30(3), 243-253. https://doi.org/10.1016/j.jpainsymman.2005.03.013

Sanders, R.A. \& Crozier, K., 2018, 'How do informal information sources influence women's decision-making for birth? A meta-synthesis of qualitative studies', BMC Pregnancy and Childbirth 18(1), 21. https://doi.org/10.1186/s12884-017-1648-2

Say, L., Chou, D., Gemmill, A., Tunçalp, Ö., Moller, A.B., Daniels, J. et al., 2014, 'Global causes of maternal death: A WHO systematic analysis', The Lancet Global Health 2(6), e323-e333. https://doi.org/10.1016/S2214-109X(14)70227-X

Simkhada, B., Teijlingen, E.R.V., Porter, M. \& Simkhada, P., 2008, 'Factors affecting the utilization of antenatal care in developing countries: systematic review of the literature', Journal of Advanced Nursing 61(3), 244-260.

Sokey, P.P., 2016, 'Media for Health Information Dissemination to Rural Communities by the Ghana Health Service. A Study of the Shai Osudoku District of the Greater Accra Region', Doctoral dissertation, University of Ghana.

Sokey, P.P. \& Adisah-Atta, I., 2017, 'Challenges confronting rural dwellers in accessing health information in Ghana: Shai Osudoku district in perspective', Social Sciences 6(2), 66. https://doi.org/10.3390/socsci6020066

Song, F.W., West, J.E., Lundy, L. \& Smith Dahmen, N., 2012, 'Women, pregnancy, and health information online: The making of informed patients and ideal mothers', Gender \& Society 26(5), 773-798. https://doi.org/10.1177/0891243212446336

Sørensen, K., Van den Broucke, S., Fullam, J., Doyle, G., Pelikan, J., Slonska, Z. et al., 2012, 'Health literacy and public health: A systematic review and integration of definitions and models', BMC Public Health 12(1), 80. https://doi. org/10.1186/1471-2458-12-80

Tang, P.C., Newcomb, C., Gorden, S. \& Kreider, N., 1997, 'Meeting the Information Needs of Patients: Results From a Patient Focus Group', in Proceedings: a conference of the American Medical Informatics Association, AMIA Fall Symposium, pp. 672-676. PMID: 9357710; PMCID: PMC2233596.

Tsehay, A.B., 2014, 'Seeking health information in rural context: Exploring sources of maternal health information in rural Ethiopia', Master's thesis, The University of Bergen.

Weinstein, R.S. \& Lopez, A.M., 2014, 'Health literacy and connected health', Health Affairs, 33(6), 1103-1104.

Van Zuuren, F.J. \& Wolfs, H.M., 1991, 'Styles of information seeking under threat: Personal and situational aspects of monitoring and blunting', Personality and Individual Differences 12(2), 141-149. https://doi.org/10.1016/0191-8869(91)90097-U

Wathen, C.N. \& Harris, R.M., 2006, 'An examination of the health information seeking experiences of women in Rural Ontario, Canada', Information Research: An International Electronic Journal 11(4), n4. https://doi.org/10.1080/ 10810730600751979

Wathen, C.N. \& Harris, R.M., 2007, “'I try to take care of it myself." How rural women search for health information', Qualitative Health Research 17(5), 639-651. https://doi.org/10.1177/1049732307301236 